\title{
Spontaneous intestinal intramural hematoma: What to do and not to do
}

\author{
Tayfun Yoldaș, Varlık Erol, Cemil Çalıșkan, Erhan Akgün, Mustafa Korkut
}

\section{ABSTRACT}

Department of General Surgery, Ege University Faculty of Medicine, İzmir, Turkey

\section{Address for Correspondence \\ Dr. Varlık Erol}

Department of General Surgery, Ege University Faculty of Medicine, İmir, Turkey Phone.: +902323904020

e-mail:

varlikerol@gmail.com

Received: 25.03 .2013

Accepted: 10.05 .2013

(C) Copyright 2013 by Turkish Surgical Association

Available online at

www.ulusalcerrahidergisi.org
Objective: Spontaneous intestinal intramural hematoma is a rare complication of anticoagulant treatment. In this study, we retrospectively evaluated 14 patients with the diagnosis of intramural hematoma of the small intestine who were followed-up and treated in our clinic, and we aimed to determine current approaches in the diagnosis and treatment of intramural hematoma.

Material and Methods: Between February 2010-October 2012, 14 patients diagnosed with small intestinal intramural hematoma were retrospectively analyzed. Nine patients were followed due to clinical findings and 5 patients underwent operation with a histopathological diagnosis of intramural hematoma.

Results: Abdominal computed tomography demonstrated ileal and jejunal wall thickening in 10 patients, while findings were consistent with mesenteric vascular disease in four. Five patients were operated due to mechanical bowel obstruction and acute abdomen. The other 9 patients were followed up with medical treatment and 8 of these patients were already using warfarin due to cardiac bypass and valve replacement.

Conclusion: Spontaneous intestinal intramural hematoma is a rare cause of small bowel obstruction due to intramural hematoma, which is encountered even more rarely. An intramural hematoma should be considered among differential diagnosis of patients who present with abdominal pain and symptoms of obstruction with a history of anticoagulant drug use and elevated International Normalized Ratio (INR) levels. Early diagnosis and medical follow-up can provide a good response to treatment in the majority of patients without requiring surgery.

Key Words: Small bowel, intramural hematoma, anticoagulant treatment

\section{INTRODUCTION}

Anticoagulant drugs are widely used for various purposes as a prophylactic agent or for treatment. Warfarin is the most frequently used of these drugs, and its most common side effect is bleeding. Intestinal intramural hematoma is located in the duodenum especially in children, whereas spontaneous intramural hematoma is often seen in the jejunum. Hemorrhagic complications of anticoagulant medications are hematuria, gastrointestinal hemorrhage, intracerebral hemorrhage, soft tissue hematoma, epistaxis, and retroperitoneal hematomas (1). Bleeding as intramural hematoma of the small intestine is rare, seen in 1 out of 2500 patients (2). Intramural hematoma of the small intestine due to use of high-dose anticoagulation is the most common form. Other risk factors are hemobilia, idiopathic thrombocytopenic purpura, leukemia, lymphoma, myeloma, chemotherapy, vasculitis, pancreatitis, and pancreatic cancer $(3,4)$. Conditions requiring surgery are serious intraluminal bleeding, bowel perforation or the presence of ischemia $(1,2)$. If diagnosis can be confirmed, conservative treatment with correction of coagulation parameters is satisfactory in most cases (5). Computed tomography (CT) is the most commonly used imaging method in diagnosis. CT findings are; wall thickening, intramural hyper-density, luminal narrowing and obstruction of the intestine (3). Hematoma is observed in order of decreasing frequency, in the jejunum (69\%), ileum (38\%) and the duodenum (23\%) (3). In this study, 14 patients with a diagnosis of intramural hematoma of the small intestine and treated at our clinics were retrospectively evaluated, and current approaches in the diagnosis and treatment of intramural hematoma was emphasized.

\section{MATERIAL AND METHODS}

Between February 2010-October 2012, 14 patients with a diagnosis of small intestinal intramural hematoma were retrospectively analyzed. Nine patients were followed due to clinical findings and 5 patients underwent operation with a histopathological diagnosis of intramural hematoma. Patient demographics (age, gender), clinical symptoms, signs, laboratory and imaging data, co-morbidities, concomitant medications, and treatment methods were assessed. 


\section{RESULTS}

Fourteen patients who were diagnosed with small bowel intramural hematoma were retrospectively analyzed. Five of the patients were male (35.7\%) and 9 were female (64.3\%). The mean age was 68 (53-78) years. Radiologically, air-fluid levels at the level of small bowel were seen on plain abdominal X-rays, on $\mathrm{CT} ; 4$ of 14 patients showed changes related to mesenteric vascular disease, and in 10 patients wall thickening of the ileal and jejunal loops were identified (Figure 1). A laparotomy was done in five patients (35.7\%) with mechanical bowel obstruction and acute abdomen, 3 of these patients underwent partial small bowel resection and end-to-end anastomosis (Figure 2). In patients who underwent resection, intramural hematoma causing obstruction and ischemic changes was observed at the level of the jejunum in 2 patients, and in the ileum in 1 patient. Pathology results of patients who had been operated showed submucosal congestion, edema, hemorrhage and ischemic changes in the small bowel. Two patients who were operated had no history of trauma or anticoagulant use. The remaining two patients were also diagnosed with small bowel intramural hematoma but they underwent laparotomy without bowel resection since the hematoma did not occlude the small bowel lumen, there were no ischemic changes and lack of severe dilatation proximal to the hematoma. The other 9 patients were followed by medical treatment with signs of partial obstruction and absence of acute abdomen. Eight of the 9 patients who were treated non-operatively were using warfarin for previous cardiac valve replacement or cardiac problems, while 1 patient was not receiving anticoagulation (Table 1). Ten of the 14 patients included in the study had a history of anticoagulation therapy (9 patients warfarin, 1 patient acetylsalicylic acid), and the INR values were elevated in all 10 patients. Neither the pa- tients who were operated nor the ones treated non-operatively were detected to have biochemical abnormalities (blood count and electrolyte levels) that reached levels that would cause complications or require close monitoring. The non-operative follow-up patients were treated with cessation of oral intake, intravenous hydration, nasogastric tube decompression, daily monitoring of coagulation parameters, electrolytes, and careful fluid replacement. Out of 14 patients who were operated and treated with medical therapy, 2 (14\%) patients had multiple organ failure and died due to cardiopulmonary arrest, whereas the other 12 (86\%) patients were discharged without any other complications.

\section{DISCUSSION}

McLauchlan has first described intestinal intramural hematoma in 1838 by autopsy of a 49 -year-old male patient (6). Then, for the first time in 1904 by Sutherland nontraumatic intestinal intramural hematoma has been reported as a case report

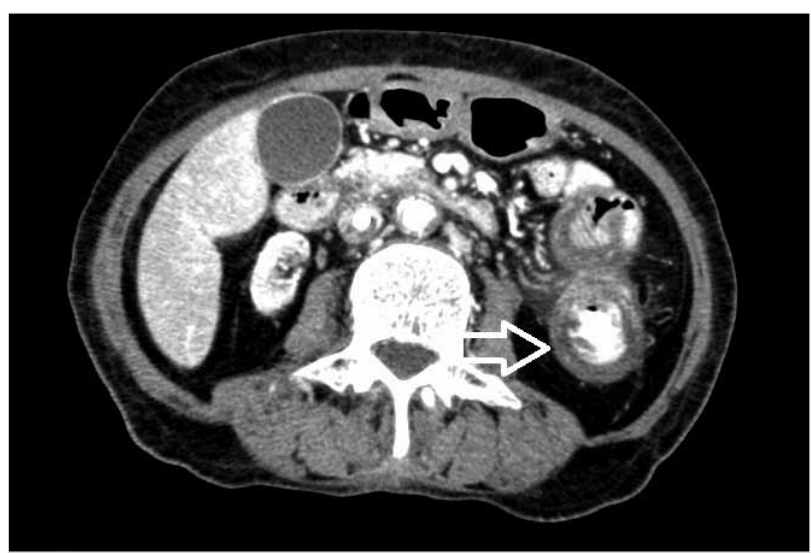

Figure 1. CT showing wall thickening in the small bowel

\begin{tabular}{|c|c|c|c|c|c|c|c|c|}
\hline Patients & Age & Gender & Co-morbidity & $\begin{array}{c}\text { Previous abdominal } \\
\text { surgery }\end{array}$ & Anticoagulation & INR & Operation & Mortality \\
\hline 1 & 63 & Male & Arrythmia & - & Warfarin & $>4.5$ & - & - \\
\hline 2 & 58 & Female & Heart valve replacement & - & Warfarin & $>4.5$ & - & - \\
\hline 4 & 70 & Female & Heart valve replacement & - & Warfarin & $>4.5$ & - & - \\
\hline 5 & 70 & Female & Cardiomyopathy & - & Warfarin & 2.9 & - & - \\
\hline 6 & 53 & Female & Hypertension & - & None & 1.1 & - & - \\
\hline 7 & 74 & Female & Heart valve replacement & - & Warfarin & 2.8 & - & - \\
\hline 9 & 78 & Female & Hypertension, diabetes & - & None & 1 & + & - \\
\hline 10 & 69 & Male & Coronary artery disease & - & Warfarin & 1.82 & + & + \\
\hline 11 & 57 & Female & $\begin{array}{l}\text { Past myocardial infarction, } \\
\text { amyloidosis, Behçet's disease }\end{array}$ & e & $\begin{array}{l}\text { Acetylsalysilic } \\
\text { acid }\end{array}$ & 2.2 & + (exploration) & + \\
\hline 12 & 76 & Male & Past myocardial infarction & - & Warfarin & 1.4 & + (exploration) & - \\
\hline 13 & 62 & Female & Hypertension & - & None & 1.1 & + & - \\
\hline 14 & 76 & Female & Heart valve replacement & - & Warfarin & $>4.5$ & - & - \\
\hline
\end{tabular}

DVT: Deep Venous Thrombosis 


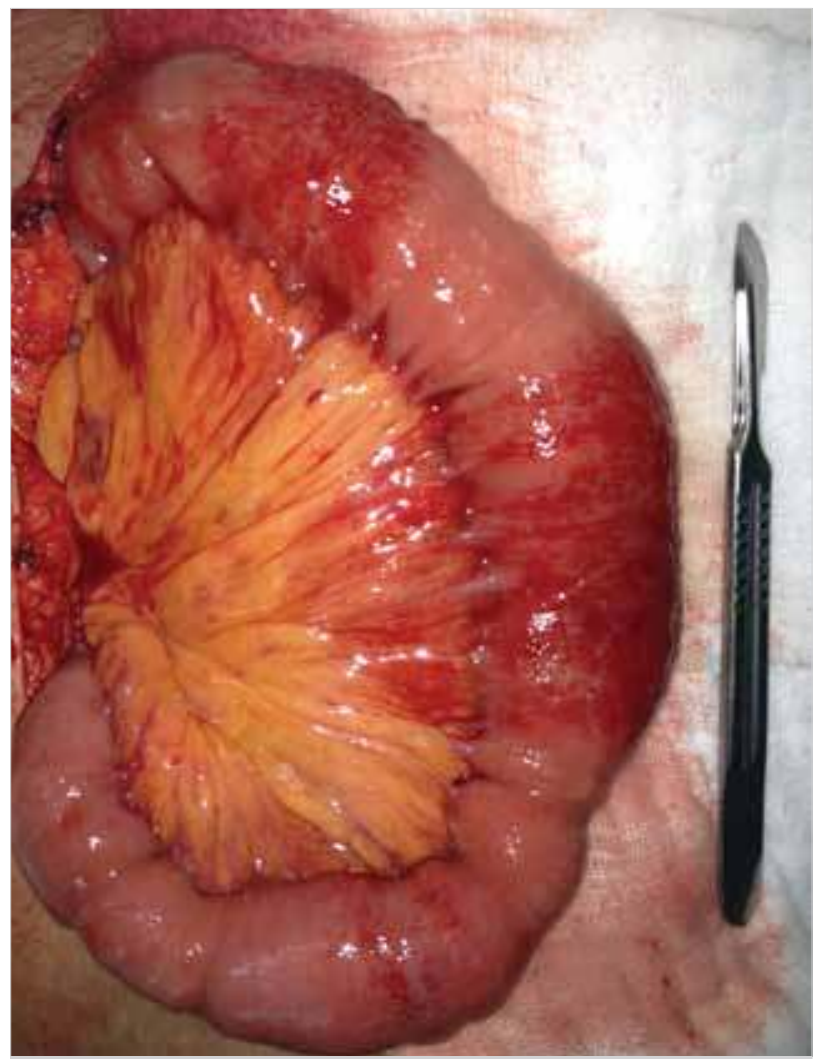

Figure 2. Operative view showing edema and hyperemia in the bowel

(7). At that time non-traumatic causes have been reported as; hemophilia, Henoch-Schönlein purpura and intussusception. However today, this situation is caused more frequently by anticoagulation treatment complication, bleeding disorders, malignancy and vasculitis (3). Spontaneous intestinal intramural hematoma is a rare complication of anticoagulant therapy and intramural hematoma induced small bowel obstruction is a condition even more rarely encountered. It is seen in small bowel most frequently in the jejunum, then in the ileum and duodenum. Intramural hematomas have also been reported in the esophagus and colon $(8,9)$. It is often seen in patients taking excess doses of anticoagulants. It is seen more common in men, and the average age is 64 (10). Male - female ratio in this study was found to be $35.7 \%-64.3 \%$. Because of its rarity, it is found as case reports in the literature, the largest series covering 13 patients 8 of which are using anticoagulants (3).

The most likely pathophysiology is the rupture of the terminal artery that arises from the mesentery and penetrates into the muscular layer of the intestinal wall. As a result, bleeding dissects the muscularis mucosa and muscular layers of the bowel wall. Usually the first symptom is abdominal pain often accompanied by nausea and vomiting $(3,4)$. Patients can also present with gastrointestinal bleeding due to rupture of the hematoma. In the presence of signs of peritoneal irritation, hematoma complications like necrosis, perforation and hemoperitoneum should be suspected. In a patient presenting with abdominal pain, presence of a history of use of anticoagulants and prolonged INR (International Normalized Ratio) should
Although ultrasound may help in diagnosis, CT is the most useful test. In this study, CT diagnosed $71.4 \%$ of patients with intestinal intramural hematoma. Patients who showed changes related to mesenteric vascular disease on CT (small bowel wall thickening and intramural air bubbles) were operated due to presence of clinical signs of peritonitis and mechanical bowel obstruction. Typical findings in abdominal CT are diagnostic, and they include circumferential wall thickening, narrowing of the lumen, hyper-density and obstruction (3). Although not specific, wall thickening reaching the submucosal layer can be seen by ultrasonography (11).

There are not enough studies to standardize treatment due to its rare clinical presentation. During treatment, anticoagulant drugs are discontinued first, bleeding parameters are tried to be normalized with vitamin $\mathrm{K}$ and fresh frozen plasma support, oral intake is stopped, and decompression is applied by nasogastric tube. In patients without signs of peritoneal irritation or complications, the clinical presentation resolves in 5-7 days with conservative treatment. Full hematoma resolution can be radiologically determined in a few weeks. If imaging findings persist longer than two months, other underlying clinical situations should be considered $(12,13)$. Early diagnosis is essential since it can provide good response to medical treatment without requiring surgery in majority of the patients. The anticoagulant therapy may be resumed after regression of the hematoma and the patient's clinical improvement. Surgical treatment is not indicated in patients with uncomplicated intramural hematoma.

\section{CONCLUSION}

Spontaneous intestinal intramural hematoma is a disease that presents as a rare complication of anticoagulant therapy, and leads to acute abdominal pathologies such as small bowel obstruction and perforation. The following should be performed in the diagnosis and treatment:

1. A history of anticoagulant therapy in combination with prolonged INR should raise suspicion in patients presenting with abdominal pain and signs of obstruction.

2. Since definitive diagnosis is not possible by radiological imaging techniques, physical examination and vital signs of the patient should be carefully evaluated on suspicion of intramural hematoma.

3. Surgical exploration should be administered to patients with; intra-abdominal hemorrhage, ischemia, perforation, peritonitis, and obstruction that does not resolve with conservative treatment $(10,14,15)$.

4. The primary treatment modality in patients without signs of peritonitis, with partial mechanical bowel obstruction should be fluid replacement and non-operative management with close follow-up.

Things not to be done are listed as follows;

1. In case of suspicious diagnosis, clinical follow-up examination should be closely monitored and the decision to operate should not be made in a hurry.

2. The possibility of developing complications (ischemia, necrosis, perforation) should be considered in patients 
with signs of peritonitis or deterioration in vital signs during follow-up and an emergency operation decision should not be delayed.

3. If any complication is not found during surgery and the patency of intestinal passage is verified, bowel resection should not be applied since there is no survival benefit.

In this study, the two patients who succumbed were in the surgical group. We believe that in patients diagnosed with intestinal intramural hematoma and whose clinical manifestations do not require emergency operations, conservative management is the most effective method of treatment.

Author Contributions: Concept - T.Y., V.E.; Design - T.Y., V.E.; Supervision - T.Y., V.E.; Funding - T.Y., V.E., C.Ç., M.K., E.A.; Data Collection and/ or Processing - T.Y., V.E.; Analysis and/or Interpretation - T.Y., V.E., C.Ç., M.K., E.A.; Literature Review - T.Y., V.E.; Writer - T.Y., V.E.; Critical Review - C.Ç., M.K., E.A.

Peer-review: Externally peer-reviewed.

Conflict of Interest: No conflict of interest was declared by the authors.

Financial Disclosure: The authors declared that this study has received no financial support.

\section{REFERENCES}

1. Hou SW, Chen CC, Chen KC, Ko SY, Wong CS, Chong CF. Sonographic diagnosis of spontaneous intramural small bowel hematoma in a case of warfarin overdose. J Clin Ultrasound 2008; 36: 374-376. [CrossRef]

2. Uzun MA, Koksal N, Gunerhan Y, Sahin UY, Onur E, Ozkan OF. Intestinal obstruction due to spontaneous intramural hematoma of the small intestine during warfarin use: a report of two cases. Eur J Emerg Med 2007; 14: 272-273. [CrossRef]
3. Abbas MA, Collins JM, Olden KW. Spontaneous intramural smallbowel hematoma: imaging findings and outcome. AJR Am J Roentgenol 2002; 179: 1389-1394. [CrossRef]

4. Birla RP, Mahawar KK, Saw EY, Tabaqchali MA, Woolfall P. Spontaneous intramural jejunal haematoma: a case report. Cases J 2008; 1: 389. [CrossRef]

5. Shaw PH, Ranganathan S, Gaines B. A spontaneous intramural hematoma of the bowel presenting as obstruction in a child receiving Low-Molecular Weight Heparin. Pediatr Hematol Oncol 2005; 27: 558-560. [CrossRef]

6. McLauchlan J. Fatal false aneurysmal tumour occupying nearly the whole of the duodenum. Lancet 1883; 2: 203-205.

7. Sutherland GA. Intussusception and Henoch's purpura. Br J Dis Child 1904; 1: 23-28.

8. Liu Y, Yang S, Tong Q. Spontaneous intramural hematoma of coIon. Clin Gastroenterol Hepatol 2011; 10: 38. [CrossRef]

9. Shimodaira M, Nakajima Y, Akiyama T, Koyama S. Spontaneous intramural haematoma of the oesophagus. Intern Med J 2011; 41: 577-578. [CrossRef]

10. Sorbello MP, Utiyama EM, Parreira JG, Birolini D, Rasslan S. Spontaneous intramural small bowel hematoma induced by anticoagulant therapy: review and case report. Clinics (Sao. Paulo) 2007; 62: 785-790. [CrossRef]

11. Rauh $P$, Uhle C, Ensberg D, Rickes $S$, Mönkemüller $K$, Fry L, et al. Sonographic characteristics of intramural bowel hematoma. J Clin Ultrasound 2008; 36: 367-368. [CrossRef]

12. Altikaya N, Parlakgümüş A, Demır Ş, Alkan Ö, Yildirim T. Small bowel obstruction caused by intramural hematoma secondary to warfarin therapy: a report of two cases. Turk J Gastroenterol 2011; 22: 199-202.

13. Carkman S, Ozben V, Saribeyoğlu K, Somuncu E, Ergüney S, Korman $\mathrm{U}$, et al. Spontaneous intramural hematoma of the small intestine. Ulus Travma Acil Cerrahi Derg 2010; 16: 165-169.

14. Jimenez J. Abdominal pain in a patient using warfarin. Postgrad Med J 1999; 75: 747-748.

15. Askey JM. Small bowel obstruction due to intramural hematoma during anticoagulant therapy, a non-surgical condition. Calif Med 1966; 104: 449-453. 